\title{
Consideration of the Necessity of Prophylactic Bypass Grafting for Anomalous Origin of the Right Coronary Artery-Based on a Case with Concomitant Left Main Trunk Disease Resuscitated from Cardiopulmonary Arrest
}

\author{
Hirotaro Sugiyama1*, Keisuke Miyajima', Kazuyoshi Hatada², Toshihiro Ishikawa², \\ Sawa Matsumoto ${ }^{3}$, Shigeo Umezawa ${ }^{3}$, Masao Takahashi ${ }^{1}$ \\ ${ }^{1}$ Department of Cardiovascular Surgery, Hiratsuka Kyosai Heart Center, Hiratsuka Kyosai Hospital, Hiratsuka, Kanagawa, Japan \\ ${ }^{2}$ Department of Cardiovascular Surgery, Odawara Municipal Hospital, Odawara, Kanagawa, Japan \\ ${ }^{3}$ Department of Cardiology, Hiratsuka Kyosai Heart Center, Hiratsuka Kyosai Hospital, Hiratsuka, Kanagawa, Japan \\ Email: *herotard1986@gmail.com
}

How to cite this paper: Sugiyama, H., Miyajima, K., Hatada, K., Ishikawa, T., Matsumoto, S., Umezawa, S. and Takahashi, M. (2017) Consideration of the Necessity of Prophylactic Bypass Grafting for Anomalous Origin of the Right Coronary ArteryBased on a Case with Concomitant Left Main Trunk Disease Resuscitated from Cardiopulmonary Arrest. World Journal of Cardiovascular Surgery, 7, 79-85.

https://doi.org/10.4236/wjcs.2017.76010

Received: May 26, 2017

Accepted: June 24, 2017

Published: June 27, 2017

Copyright $\odot 2017$ by authors and Scientific Research Publishing Inc. This work is licensed under the Creative Commons Attribution International License (CC BY 4.0).

http://creativecommons.org/licenses/by/4.0/ (c) (i) Open Access

\begin{abstract}
Anomalous origin of the right coronary artery is a rare congenital anomaly, but is associated with sudden death. Originating from the opposite sinus of Valsalva, an interarterial course and an intramural course are especially considered as the risk factor for fatal cardiac events. Surgical indication remains controversial because many patients are asymptomatic. A 52-year-old man with anomalous origin of the right coronary artery with an interarterial course concomitant with the left main trunk disease was resuscitated from cardiopulmonary arrest. It was likely to be attributed to the left main trunk disease, but anatomical structure of the right coronary artery suggests its possible involvement. Prophylactic bypass grafting for the right coronary artery was performed using saphenous vein graft without ligating native vessel to prevent future cardiac events, as well as revascularization of the left main trunk disease. All grafts were patent in one-year follow-up coronary angiography. Any cardiac event has not occurred.
\end{abstract}

\section{Keywords}

Anomalous Origin of the Right Coronary Artery, Prophylactic Bypass

Grafting, Saphenous Vein Graft, Left Main Trunk Disease, Sudden Death

\section{Introduction}

Anomalous origin of the coronary artery (AOCA) from the opposite sinus of Valsalva is a rare congenital anomaly, but is related to sudden death. Its reported 
incidence discovered in patients who underwent coronary angiography is $0.64 \%$ - $1.6 \%$ [1]. In particular, anomalous origin of the right coronary artery originating from the left sinus of Valsalva with an interarterial course (AOCA-R) is the most common accounting for $0.17 \%$ [1]. Surgical intervention is indicated in symptomatic patients. We present a patient with AOCA-R concomitant with the left main trunk (LMT) disease resuscitated from cardiopulmonary arrest (CPA). Bypass grafting for the right coronary artery (RCA) was prophylactically performed to prevent future cardiac events.

\section{Case Report}

A 52-year-old Japanese male patient with a history of hypertension and hyperlipidemia was brought to our hospital after he was resuscitated from CPA while carrying a portable shrine at local festival. Electrocardiagram showed ST-segment elevation in lead aVR. On his admission, his conscious level was E1VtM1 in Glasgow Coma Scale, blood pressure was $110 / 60 \mathrm{mmHg}$ and heart rate was $100 /$ min. Echocardiography revealed an ejection fraction of $64.1 \%$ with no asynergy of ventricular wall motion (Figure 1). Coronary angiography (CAG) showed AOCA-R (Figure 2(a)). Left circumflex artery (LCX) was not detected, indicating hypoplastic LCX (Figure 2(b)). Maximum CK and CK-MB were 963 and 101 respectively. Therapeutic hypothermia was successfully undergone. Preoperative 3D computed tomography showed AOCA-R coursing between aorta and pulmonary artery and LCX originating from normal site, but was occluded from the origin (Figures 2(c)-(e)). Massive thrombus existed from the LMT to the proximal segment of the left anterior descending artery (LAD). Stable plaque existed on the RCA, but significant stenosis was not revealed in neither CAG nor optical coherence tomography. We performed off-pump coronary artery bypass grafting $(\mathrm{OPCAB})$ on the $37^{\text {th }}$ day: left internal thoracic artery-LAD, radial artery-diagonal branch-posterolateral branch, saphenous vein graft (SVG)-RCA \#3 (Figure 3(a)). Following general anesthesia, OPCAB was performed using DONUT Heart Stabilizer [2] through median sternotomy. Mean blood flow and Pulsatility

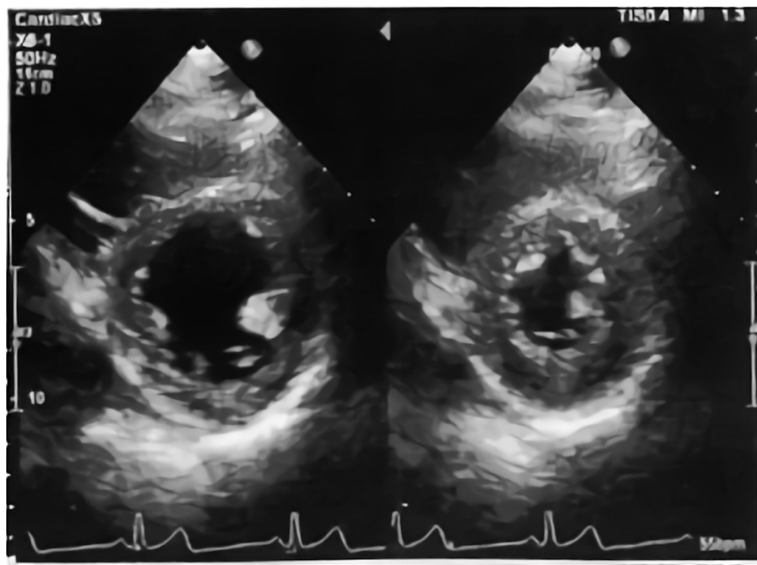

Figure 1. Echocardiography reveals an ejection fraction of $64.1 \%$ with no asynergy of ventricular wall motion. 


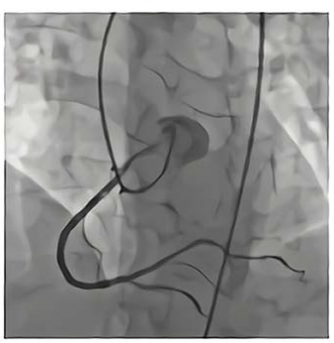

(a)

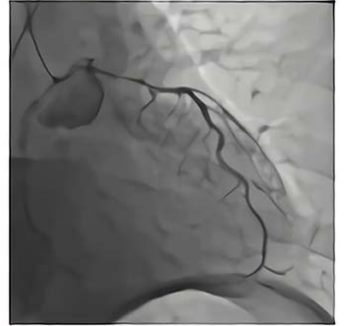

(b)

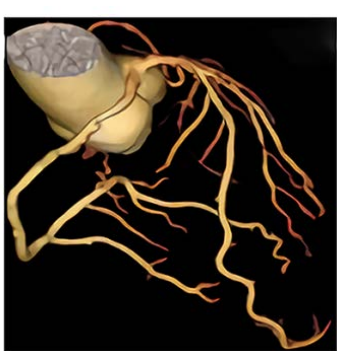

(c)

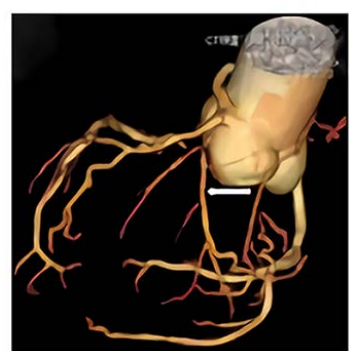

(d)

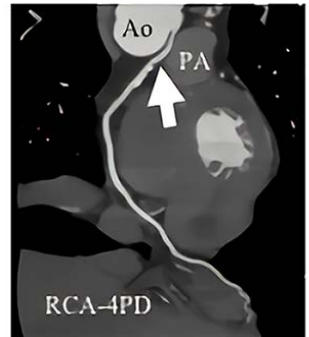

(e)

Figure 2. (a) Coronary angiography performed on his admission shows anomalous origin of the right coronary artery; (b) Hypoplastic left circumflex artery was indicated then as left circumflex artery was not detected; (c) 3D computed tomography shows anomalous origin of the right coronary artery originating from the left sinus of Valsalva; (d) White arrow indicates left circumflex artery. The origin of left circumflex artery was occluded. Blood supply was dependent on collateral flow that comes from the right coronary artery; (e) Preoperative contrast-enhanced computed tomography shows the right coronary artery originating from the left sinus of Valsalva almost tangent to an aortic wall coursing between aorta and pulmonary artery. White arrow indicates coronary ostium deformed as a result of compression by pulmonary artery.

Index (PI) were measured by transit time flow meter at SVG (118 $\mathrm{ml} / \mathrm{min}, 1.5)$, native RCA with SVG clamped ( $47 \mathrm{ml} / \mathrm{min}, 2.8$ ) and native RCA with SVG open (6 $\mathrm{ml} / \mathrm{min}, 17.8$ ). (A PI of more than 5 and a systolic spike in the shape of waveform are considered as an evidence of graft occlusion.) Therefore, the native RCA has not been ligated. Intraoperative fluorescence SPY ${ }^{\mathrm{TM}}$ (NOVADAQ, Ontario, Canada) imaging revealed all the grafts were patent (Figure 3(a)) [3]. The patient was extubated at the operation room just after the operation. All the grafts were patent in early postoperative 3D computed tomography (Figure 3(b)). He was discharged 18 days after the operation. CAG performed one year after the surgery reveled all the grafts were patent (Figure 3(b)). Cardiovascular event has not been reported yet.

\section{Discussion}

AOCA-R has been known as the cause of sudden death especially on exertion. It frequently occurs without any symptoms and signs [4]. Surgical criteria are still controversial. As blood pressure goes up, cardiac output increases, making an angle between the aortic lumen and coronary ostium more acute (generally < $\left.45^{\circ}\right)$. Coronary ostium gets occluded in especially diastole, which is called a slitlike orifice [5]. The coronary artery is compressed toward main pulmonary 


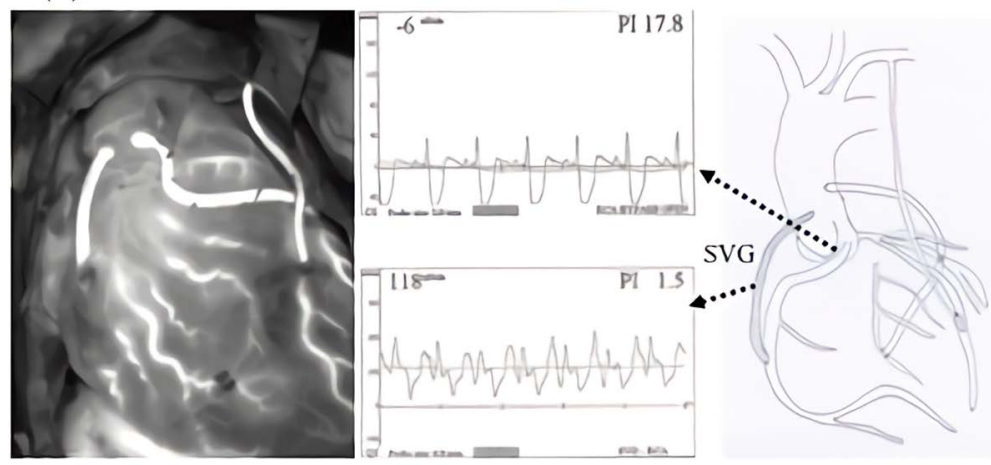

(a)

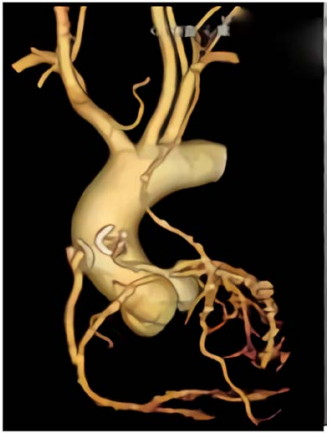

(b)

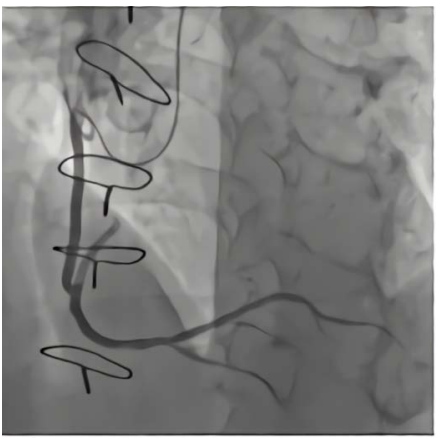

(c)

Figure 3. (a) Short saphenous vein graft was anastomosed to the proximal segment of the right coronary artery. Intraoperative fluorescence SPY ${ }^{\mathrm{TM}}$ (NOVADAQ, Ontario, Canada) imaging reveals all grafts are patent. Transit time flow meter shows adequate flow at the graft; (b) Early postoperative 3D computed tomography shows all the grafts are patent; (c) Coronary angiography undergone one year after the operation shows the saphenous vein graft is patent.

artery, which results in critical reduction in coronary blood flow. Mayo clinic reported that surgery is indicated for a symptomatic patient or a patient with positive result in stress testing who hope for active lifestyles [6]. ACC/AHA guideline shows that surgery is recommended for a patient with evidence of ischemia (Level of evidence B) [7]. However, some believe that AOCA-R alone is a strong enough indication, [6] because it may cause fatal cardiac events regardless of symptoms and apparent stenosis [8]. Surgical procedure includes unroofing, reimplantation into the correct sinus, pulmonary translocation and coronary artery bypass grafting (CABG). CABG is selected for patients with concomitant atherosclerotic disease or with anatomy not appropriate to other procedures [6]. In the reported case, CPA was probably attributed to the LMT disease. However, the RCA originating from the left sinus of Valsalva almost tangent to an aortic wall with an interarterial course (Figure 2(e)) is also considered as the cause of event. CABG was undergone prophylactically for the RCA to prevent sudden death, given anatomical structure, past history of CPA and his willingness to join festival again. Graft selection matters as selected graft must provide the best potential long-term patency. An arterial graft is often preferred for especially younger patients. However, anastomosing arterial graft to the 
nonoccluded vessel may result in competitive flow and graft occlusion, which recommends ligating native vessel. Fedoruck LM et al. reported right internal thoracic artery (RITA) is not suitable for a graft anastomosed to the nonoccluded artery without ligation [9]. Other previous case reports show RITA is selected in younger patients. Three out of five cases in which RITA was anastomosed to the nonoccluded RCA without ligating native vessel show early graft occlusion. (Table 1) SVG is often used for a lesion with mild stenosis because their larger diameter keeps resting flow rates higher than other grafts [4], which may prevent the early occlusion and stenosis. SVG may be the choice for patients with AOCA-R regardless of whether significant stenosis exists on the RCA and whether to ligate native vessel (Table 1). We selected short SVG. Ligating native RCA was avoided as graft flow was satisfactory in intraoperative transit time flow meter. Long-term patency of vein grafts is generally inferior to that of arterial grafts, so prognosis of bypass grafting for AOCA-R using vein graft is uncertain. Follow-up is ongoing. Surgical indication depends on symptoms, anatomical structure, concomitant atherosclerotic disease and patient's willingness. We consider SVG as the possible graft selection for patients with AOCA-R not only to ensure distal coronary blood flow but to preserve native vessel without significant stenosis. Distal protection may prevent future atherosclerotic disease. AOCA-R is a rare, potentially fatal anomaly in which mechanism of cardiac ischemia and sudden death has not been well understood. Sudden death would happen regardless of symptoms, apparent stenosis and the result of stress testing. Each patient should be managed adequately on a case by case basis.

Table 1. Coronary artery bypass grafting (CABG) was performed in patients with anomalous origin of the right coronary artery (RCA). Graft selection, whether to ligate native RCA and outcome associated with CABG.

\begin{tabular}{|c|c|c|c|c|c|c|}
\hline Author (Year) & Age & Sex & Graft & $\begin{array}{c}\text { Ligation of native } \\
\text { RCA }\end{array}$ & Graft occlusion & $\begin{array}{l}\text { Re-operaion } \\
\text { procedure }\end{array}$ \\
\hline Shah et al. (2000) [10] & 50 & M & RITA & Yes & none & none \\
\hline Reul et al. (2002) [11]† & Unknown & Unknown & RITA & No & 1 month & CABG \\
\hline Reul et al. (2002) [11] & Unknown & Unknown & RITA & No & None & None \\
\hline Fedoruck et al. (2007) [9] & 33 & M & RITA & No & 5 month & Reimplantation \\
\hline Fedoruck et al. (2007) [9] & 26 & $\mathrm{~F}$ & RITA & No & 7 month & Unroofing \\
\hline Matsuda et al. (2012) [12] & 58 & $\mathrm{~F}$ & RITA & Yes & None & None \\
\hline Izghi et al. (2014) [13] & 25 & M & RITA & Yes & None & None \\
\hline Fuglsang et al. (2015) [14] & 39 & $\mathrm{~F}$ & RITA & No & None & None \\
\hline Bett et al. (1985) [15] & 29 & M & SVG & No & None & None \\
\hline Reul et al(2002) [11] & Unknown & Unknown & SVG & Yes & None & None \\
\hline Reul et al. (2002) [11] & Unknown & Unknown & SVG & Yes & None & None \\
\hline Reul et al. (2002) [11 $]^{\dagger}$ & Unknown & Unknown & SVG & Yes & None & None \\
\hline Naruse et al. (2012) [16] & 77 & M & SVG & No & None & None \\
\hline
\end{tabular}

${ }^{\dagger}$ The same patient; RITA: right internal thoracic artery; SVG: saphenous vein graft. 


\section{Conclusion}

Prophylactic bypass grafting using SVG is feasible for patients with AOCA-R concomitant with the LMT disease in that both future cardiac events and atherosclerotic disease may be prevented. Competitive flow was avoided without ligation of the native RCA.

\section{References}

[1] Yamanaka, O. and Hobbs, R.E. (1990) Coronary Artery Anomalies in 126,595 Patients Undergoing Coronary Arteriography. Catheterization and Cardiovascular Diagnosis, 21, 28-40. https://doi.org/10.1002/ccd.1810210110

[2] Takahashi, M., Yamamoto, S. and Tabata, S. (1997) Immobilized Instrument for Minimally Invasive Direct Coronary Artery Bypass: MIDCAB Doughnut. The Journal of Thoracic and Cardiovascular Surgery, 114, 80-82. https://doi.org/10.1016/S0022-5223(97)70063-1

[3] Takahashi, M., Ishikawa, T., Higashidani, K. and Katoh, H. (2004) SPY ${ }^{\mathrm{TM}}$ : An Innovative Intra-Operative Imaging System to Evaluate Graft Patency during Off-Pump Coronary Artery Bypass Grafting. Interactive Cardiovascular and Thoracic Surgery, 3, 479-483. https://doi.org/10.1016/j.icvts.2004.01.018

[4] Taylor, A.J., Rogan, K.M. and Virmani, F.R. (1992) Sudden Cardiac Death Associated with Isolated Congenital Coronary Artery Anomalies. Journal of the American College of Cardiology, 20, 640-647. https://doi.org/10.1016/0735-1097(92)90019-J

[5] Krasuski, R.A., Magyar, D., Hart, S., Kalahasti, V. and Lorber, R. (2011) Long-Term Outcome and Impact of Surgery on Adults with Coronary Arteries Originating from the Opposite Coronary Cusup. Circulation, 123, 154-162. https://doi.org/10.1161/CIRCULATIONAHA.109.921106

[6] Davies, J.E., Burkhart, H.M., Dearan, J.A., Suri, R.M. and Phillips, S.D. (2009) Surgical Management of Anomalous Aortic Origin of a Coronary Artery. The Annals of Thoracic Surgery, 88, 844-848. https://doi.org/10.1016/j.athoracsur.2009.06.007

[7] Warnes, C.A., Williams, R.G., Bashore, T.M., Child, J.S. and Connolly, H.M. (2008) ACC/AHA 2008 Guidelines for the Management of Adults with Congenital Heart Disease: A Report of the American College of Cardiology/American Heart Association Task Force on Practice Guidelines. Circulation, 118, 714-833. https://doi.org/10.1161/CIRCULATIONAHA.108.190690

[8] Kaku, B. (1996) Clinical Features and Prognosis of Patients with Anomalous Origin of the Coronary Artery. Journal of the Juzen Medical Society, 105, 496-505. https://doi.org/10.1253/jcj.60.731

[9] Fedoruk, L.M., Kern, J.A., Peeler, B.B. and Kron, I.L. (2007) Anomalous Origin of the Right Coronary Artery: Right Internal Thoracic Artery to Right Coronary Artery Bypass Is Not the Answer. The Journal of Thoracic and Cardiovascular Surgery, 133, 456-460. https://doi.org/10.1016/j.jtcvs.2006.10.011

[10] Shah, A.S., Milano, C.A. and Lucke, J.P. (2000) Anomalous Origin of the Right Coronary Artery from the Left Coronary Sinus: Case Report and Review of Surgical Treatments. Cardiovascular Surgery, 8, 284-286. https://doi.org/10.1016/S0967-2109(00)00025-9

[11] Reul, R.M., Cooley, D.A., Hallman, G.L. and Reul, G.J. (2002) Surgical Treatment of Coronary Artery Anomalies. Texas Heart Institute Journal, 29, 299-307.

[12] Matsueda, T., Osumi, M., Tatsuo, M., Kurushima, A., Otani, T. and Fukumura, Y. 
(2012) A Case of Coronary Artery Bypass Grafting for Anomalous Aortic Origin of a Coronary Artery. Japanese Journal of Cardiovascular Surgery, 41, 257-261. https://doi.org/10.4326/jjcvs.41.257

[13] Izgi, C., Feray, H., Erdem, G. and Kaya, Z. (2014) Anomalous Origin and Interarterial Course of Right Coronary Artery Associated with Angina and Proven Ischemia. The International Journal of Angiology: Official Publication of the International College of Angiology, 23, 271-274. https://doi.org/10.1055/s-0033-1349165

[14] Fuglsang, S., Heiberg, J., Jørgen, B. and Hjortdal, V.E. (2015) Anomalous Origin of the right Coronary Artery with an Interarterial Course and Intramural Part. International Journal of Surgery Case Reports, 14, 92-94. https://doi.org/10.1016/j.ijscr.2015.07.018

[15] Bett, J.H.N., O’Brien, M.F. and Murray, P.J.S. (1985) Surgery for Anomalous Origin of the Right Coronary Artery. British Heart Journal, 53, 459-461. https://doi.org/10.1136/hrt.53.4.459

[16] Naruse, Y., Sato, A., Kakefuda, Y., Hoshi, T., Imai, A., Tokunaga, C., Sakakibara, Y. and Aonuma, K. (2012) Anomalous Origin of the Right Coronary Artery from the Left Sinus of Valsalva in an Elderly Man Life-Threatening Worsening of Angina after Left Lung Lobectomy. Circulation, 125, 1021-1024.

https://doi.org/10.1161/CIRCULATIONAHA.112.096313

\section{Scientific Research Publishing}

Submit or recommend next manuscript to SCIRP and we will provide best service for you:

Accepting pre-submission inquiries through Email, Facebook, LinkedIn, Twitter, etc. A wide selection of journals (inclusive of 9 subjects, more than 200 journals)

Providing 24-hour high-quality service

User-friendly online submission system

Fair and swift peer-review system

Efficient typesetting and proofreading procedure

Display of the result of downloads and visits, as well as the number of cited articles

Maximum dissemination of your research work

Submit your manuscript at: http://papersubmission.scirp.org/

Or contact wjcs@scirp.org 